sidad emitir el Kiai, o grito penetrante que paraliza al oponente, las formas de caer o Ukemis, aunque no explica los detalles técnicos, y acaba describiendo las técnicas fundamentales del Aikido, así como las diferentes formas, o situaciones de adiestramiento.

Sigue la tercera parte, exponiendo la filosofía en la que Morihei Ueshiba quiso fundamentar su arte marcial. Morihei era un hombre profundamente religioso, y cada mañana y cada noche ofrecía sus plegarias al "Gran Espíritu del Aikido", pues estaba totalmente persuadido de que toda persona es "un templo viviente de lo divino". También practicaba con asiduidad el rito de "Misogi", o purificación del cuerpo y de la mente, bajo el chorro frío del agua de una cascada, que simboliza el "regreso a un estado de pureza sencilla", y cuyo objetivo es "recrear el mundo continuamente, para hacer que cada día sea nuevo". En consecuencia, proponía a sus alumnos que cultivasen su espíritu por medio de la plegaria y la meditación, para llegar al conocimiento de si mismos, como la mejor vía para asimilar la filosofía del Aikido.

Entre otros muchos propósitos, en los escritos del creador del Aikido se encuentran estas enseñanzas: "La verdadera victoria es la victoria de uno mismo, y aprender a ganar sin luchar". "El Universo es nuestro gran maestro". "El Aiki es una fuente inagotable de sabiduría". "Hemos de aprender a unirnos con la fuerza vital". "Lo divino no existe sólo allá arriba, en el cielo, sino que está aquí mismo, y por tanto estamos siempre en un estado de gracia divina". "La práctica del Aikido es un acto de fe, una creencia en el poder de la no-violencia". "En el Budo verdadero los adversarios no existen, no hay enemigos".

La lectura de las páginas que contienen esta filosofía inducen a la reflexión y a constatar que una gran parte de los aikidokas de hoy tampoco han entendido el mensaje de Ueshiba, por más que todos presumen de seguir la Vía del Aikido. Claro que, en su descargo, se podría decir que no abundan los maestros que enseñen de verdad el modo de aplicar estas enseñanzas a la vida cotidiana.

La última o cuarta parte del libro es la más breve y se limita a dar noticia de las principales escuelas, que a la muerte de Ueshiba fueron creando sus principales alumnos, tales como Iwama Ryu, de Morihiro Saito; Ki society Aikido, de Koichi Tohei; Yoshinkan Aikido, de Gozo Shioda; Tomiki Aikido, de Kenji Tomiki; y Yoseikan Budo, de Mochizuki. Sigue una extensa bibliografía de libros en inglés sobre el arte del Aikido y un glosario de términos japoneses propios del Budo, y su traducción al español. El libro está ilustrado con abundantes fotos históricas de Morihei Ueshiba practicando Aikido, en diferentes épocas de su vida, y algunas caligrafías con sentencias filosóficas, realizadas por él.

También aparecen fotos de John Stevens realizando técnicas de Aikido.

El lector no encontrará en esta pequeña obra, por tanto, series técnicas de fotos demostrando la ejecución de las técnicas del programa de grados, ya que no es un libro técnico, sino un pequeño homenaje de reconocimiento que el autor quiere rendir a su apreciado maestro Morihei Ueshiba.

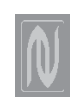

\section{Qi Gong, La Vía del Sosiego}

Por Liu Dong

Barcelona: Editorial Kairós, 2000

178 páginas, $14 \times 22 \mathrm{~cm}$. Ilustraciones I.S.B.N.: 84-7245-474-6 $12 €$

Disponible en:

Editorial Kairós

C/ Numancia, 117-121

08029 Barcelona (España)

Telf.: +34 4949440

Fax: +34 4105166

E-mail: info@editorial.com

http://www.editorialkairos.com

\section{Revisión por Héctor P. Fariña López}

Estamos frente a un libro dividido en dos partes. Una primera y claramente predominante, de carácter filosóficodivulgativo, donde el autor defiende y diferencia lo que entiende por verdadero Qi Gong, que ya desde el Prefacio anuncia como "Una forma de comportamiento cuya justificación se basa en un gran pensamiento filosófico, y que tiene como objetivo mostrarnos el camino hacia el conocimiento de la naturaleza humana, permitirnos tomar conciencia del valor de la vida y de sus límites, y guiarnos por la senda de la sabiduría”. Si bien habla del Qi Gong como parte de la Medicina Tradicional China, vemos que este va mucho más allá de sus fines preventivos y/o terapéuticos.

En esta primera parte se desarrollan conceptos de la medicina Tradicional China enlazados con lo que denomina "trípticos fundamentales de la filosofía china", como "las tres joyas del cielo, tierra y ser humano, las tres armonizaciones del Qi Gong, los tres niveles del pensamiento, la apertura de los tres puntos, etc.", terminando con las "tres prácticas del Qi Gong", donde diferencia una vez mas lo que considera una verdadera práctica frente al Qi Gong de las Artes Marciales o al Qi Gong Musical. El primero porque no es seguro que sea beneficioso para la salud si se priman objetivos marciales, error que no cometerán, según el autor, los verdaderos Maestros de estas Artes, y en el segundo por ser unos simples ejercicios de relajación donde, por ejemplo, la música no permite la quietud mental indispensable para una verdadera práctica. También cita las diferentes Escuelas de la Antigüedad, ya que la denominación de Qi Gong es relativamente reciente y engloba diferentes sistemas.

En esta primera parte siempre están presentes referencias al pensamiento Taoísta y a algo muy habitual en él como son las constantes alusiones a los antepasados y a la antigüedad, e incluso explicaciones de como fueron originalmente estas prácticas o cómo sus antiguos practicantes llegaron a descubrir aspectos como por ejemplo las "horas sensibles" para su ejecución de acuerdo a las variaciones cíclicas en la naturaleza y en el cuerpo (YinYang), su representación con los hexagramas, las influencias del clima, estaciones, fenómenos atmosféricos, etc.

Son constantes las relaciones con los meridianos de acupuntura, lo que hace que quien no tenga cierto conocimiento de ellos se encuentre falto de información, y también hay algunas 
referencias a una obra anterior del autor.

Se hace especial hincapié en la idea de conseguir un "espíritu adecuado" para la práctica, esto es, la consecución de un "corazón sensibilizado" para lograr la comprensión necesaria y por ende una correcta ejecución de los movimientos, idea que en occidente cuesta asimilar en ese orden. Echo en falta en el libro cierto componente "racional" que deje ver que los objetivos de este sistema pueden alcanzarse también en una cultura diferente de la de sus orígenes, lo cual posiblemente necesitará métodos de acercamiento diferentes. Lo echo en falta dado que el autor ha sido profesor universitario en Harvard y en el hospital Marmottan de Francia.

La segunda de la obra parte contiene los métodos terapéuticos. Tres series del método propio del autor donde se echa en falta un mayor detalle en los movimientos si el objetivo es ser una guía, y acompañados de fotografías de poca calidad. El primero apunta al trabajo básicamente de la columna vertebral, el segundo dirigido fundamentalmente a la mujer y el tercero, este con dibujos del típico buda obeso, indicado para problemas de insomnio. Para finalizar, dos series de ejercicios basados en textos clásicos que se remontan al sistema trasmitido por $\mathrm{Da} \mathrm{Mo}$ (Bodhidarma) en el celebre templo de Shaolin y realizados en el ámbito del Budismo Chan (Zen) hasta su "combinación" con los provenientes del Taoísmo que el autor atribuye al Monje Taoísta $\mathrm{Zi} \mathrm{Yi,} \mathrm{como} \mathrm{así} \mathrm{también} \mathrm{la}$ autoría de uno de los textos clásicos, el $\chi_{i}$ Sui Jing, que junto con el de Da Mo, el Yi Jin Jing, formarían el Yi Jin Xi Sui Jing del que se exponen estas series. Cabe destacar que otros autores especialistas atribuyen ambos textos clásicos a Da Mo, siendo estas dicotomías muy habituales en el ámbito del Arte Marcial de origen chino, entre otras razones, por ser gran parte de su acervo trasmitido de forma oral y por la dificultad de encontrar correctas traducciones.

Finalmente he de decir que, en mi opinión, es un libro que puede aportar una visión no diferente pero si mas "integral” del Qi Gong, que puede interesar a estudiantes, principiantes tanto de Qi Gong como de artes marciales en general, ya que objetivos tan "nobles" como los que presenta el autor son, en mayor o menor grado, asociados también a éstas e incluso forman parte de su contenido. No está de más decir que también espero que los lectores tengan la comprensión necesaria para ver que estos objetivos requieren, además de un contenido adecuado, la guía de un verdadero Maestro, es decir, alguien con sobradas virtudes humanas y sobre todo docentes, ya que no los fines de las artes marciales se alcanzan por el mero hecho de practicar tal o cual disciplina.

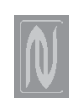

\section{Tai Chi Chuan. Aplicaciones mar- ciales. Estilo Yang avanzado}

Por el Dr. Yang Jwing-Ming

Móstoles (Madrid): Arcano Books, 2000

413 páginas. $24 \times 17 \mathrm{~cm}$. Ilustraciones I.S.B.N.: 84-89897-38-7 • $22 €$

Disponible en:

Distribuciones y Ediciones Alfaomega

C/ Alquimia, 6. P.I. Los Rosales

28933 Móstoles, Madrid (España)

Telf.: +34916145346

Fax: +34916184012

E-mail: editorial@alfaomega.es

http://www.alfaomega.es/

Revisión por Juan Pan González.

En esta ocasión, el Dr. Yang Jwing Ming nos ofrece una obra que nos acerca al aspecto marcial del Tai Chi Chuan estilo Yang, dirigido hacia todo practicante que desee conocer la aplicación marcial de las diferentes técnicas, así como el proceso a seguir en el entrenamiento. Este libro, escrito con un lenguaje claro y de fácil comprensión, completa otro de sus libros, Tai Chi Theory and Martial Power, donde se exponían los principios y las teorías del Tai Chi Chuan. Aun así, es necesario que el lector este familiarizado con algunos conceptos propios del estilo, como el yi, chi y jin.

El libro se estructura en cinco capítulos, donde se va explicando el proceso que una persona debería ir siguiendo para poder llegar a dominar los aspectos marciales del Tai Chi Chuan y convertirse en un maestro. Tras una pequeña introducción, en la que el autor nos da una serie de indicaciones y consejos para llegar a ser buenos practicantes y hacer un buen uso del libro, nos invita a reflexionar sobre el objetivo de nuestro entrenamiento, ya que el objetivo buscado dentro de cualquier arte marcial determina el tipo de entrenamiento a seguir.

En el capitulo 2 expone las aplicaciones marciales de las diferentes técnicas que componen la forma estilo Yang. Realiza una breve explicación del significado de cada técnica, lo que nos da una primera idea del sentimiento de estos movimientos. Posteriormente describe la ejecución del movimiento, paso a paso, y muestra las posibles aplicaciones prácticas, agrupándolas en 3 categorías: Shuai Jiao (derribar al enemigo), Qin $N a$ (inmovilización y control de las articulaciones) y Dian Xue (golpeo y presión de puntos de acupuntura).

El capitulo 3 se centra en el siguiente paso, la práctica del empuje de manos, explicando los aspectos teóricos y prácticos de este tipo de entrenamiento, así como algunas aplicaciones marciales derivadas de los movimientos básicos, con una y dos manos. Este entrenamiento desarrolla la sensibilidad para sentir y comprender las intenciones del adversario por medio del tacto. Para desarrollar esta habilidad de escuchar y comprender las intenciones de un adversario con sólo tocarlo, también propone el entrenamiento con un balón de madera, que sirve para aprender las tácticas de adherirse y pegarse, por medio de movimientos circulares con los dedos, manos, muñecas y antebrazos, tan característicos de las artes marciales internas. Cuando el alumno sabe escuchar y comprender, ha de aprender a neutralizar la técnica, guiarla y controlarla, para lo que el autor nos enseña una serie de ejercicios básicos, siempre con sus posibles aplicaciones marciales.

Después de este aprendizaje se practica la serie de dos hombres de Tai Chi, explicada en el capítulo 4. Este entrenamiento sirve como conexión entre el empuje de manos y el estilo libre. Nos enseña cómo sentir las 